\title{
Uma visão analítico-comportamental do uso de cocaína*
}

\section{An analytical-behavioral vision of cocaine} use

Bruna Lemes Cafure

* Recebido em: 28/04/15. Aprovado em: 23/09/15.

1 Bacharel e mestre em Psicologia pela (UFMS).

\section{Resumo}

A cocaína já foi empregada com fins terapêuticos, porém hoje é considerada uma droga ilícita na maioria dos países e sua comercialização acarreta problemas de saúde e segurança pública. O objetivo deste trabalho teórico foi fazer uma análise sobre as variáveis que mantêm o uso da droga para colaborar para o desenvolvimento de métodos mais eficazes no tratamento do usuário de substâncias psicoativas. Discute-se que recorrer a explicações apenas fisiológicas não tem sido atitude suficiente para explicar o comportamento do uso de drogas e concluiu-se que, para uma eficácia no tratamento do usuário, é necessária uma visão ampla e que considere a história de reforçamento do sujeito bem como o ambiente no qual ele está inserido.

Palavras-chave: Análise do Comportamento. Uso de drogas. Cocaína. Droga.

\begin{abstract}
Cocaine has been used for therapeutic purposes, but today is considered an illegal drug in most countries and their marketing brings health and public safety problems. The objective of this work was to make a theoretical analysis of the variables that hold the drug to contribute to the development of more effective methods in the user Treatment of psychoactive substances. It is argued that use only physiological explanation has not been enough action to explain the drug use behavior and it was concluded that, for efficiency on the user's treatment, it is necessary a broad view and to consider the reinforcement history subject as well as the environment in which it is inserted.
\end{abstract}

Keywords: Behavior Analysis. Use of drugs. Cocaine. Drug. 


\section{Introdução}

O uso não terapêutico de fármacos, de acordo com Fuchs, Wannmacher e Ferreira (2006, p. 605), se caracteriza pelo "emprego de substâncias que exercem influência sobre o sistema nervoso central com o intuito de produzir emoções e sensações gratificantes, não necessariamente iguais aos efeitos terapêuticos". Segundo Carlson (2002, p. 583), o termo "adicção" vem da palavra latina addicere, que quer dizer "condenar". E segue dizendo que "alguém que é adicto de uma droga está, condenado, de alguma maneira, a uma pena de escravidão involuntária, sendo obrigado a suprir as necessidades de sua dependência a ela". Sobre a abstinência, o autor diz que são aqueles sintomas que ocorrem quando a droga deixa de ser consumida e se caracterizam pela ocorrência de "sintomas opostos àqueles efeitos agradáveis produzidos pela droga de abuso" que são "causados pela presença de mecanismos compensatórios" (CARLSON, p. 589).

O Centro Brasileiro de Informações Sobre Drogas Psicotrópicas (CEBRID) em conjunto com a Universidade Federal de São Paulo (UNIFESP) em 2002, por meio de um levantamento domiciliar do uso de drogas psicotrópicas nas 107 maiores cidades do país revelou que, de 8.589 entrevistados, 2,3 \% já haviam feito uso de cocaína durante a vida, o que equivalia, em 2002, quando a pesquisa foi realizada, a aproximadamente 1.076 .000 de pessoas no país. Dos entrevistados com faixa etária entre 25 e 34 anos, 4,4\% já fizeram uso de cocaína durante a vida (CARLINI et al., 2002).

Segundo Carlson (2002), a cocaína acarreta consequências para o sujeito que a usa, podendo desencadear comportamento psicótico, dano cerebral e morte por superdosagem, entre muitos outros danos à saúde. Seu consumo por gestantes pode resultar no nascimento de bebês com danos cerebrais e problemas psicológicos. Além do risco de contrair AIDS e outras doenças por quem as consome intravenosamente. É importante lembrar que, além dos problemas à saúde do usuário, a cocaína também traz problemas sociais graves, pois provoca mortes, aumenta a violência urbana e corrompe o sistema policial e judiciário, caracterizando-se, também, como uma questão de segurança pública.

\section{Objetivo}

O objetivo deste trabalho teórico foi fazer análise sobre as variáveis que mantêm o uso da droga para colaborar para o desenvolvimento de métodos mais eficazes no tratamento do usuário de substâncias psicoativas e consequente melhoria da vida da coletividade, visto que o uso de drogas não é apenas um problema de saúde, mas também de segurança pública.

\section{Desenvolvimento}

A cocaína, de acordo com Cardoso e Sabbatini (1999), foi sintetizada em 1859 com base no princípio ativo da planta Erythoxylon coca, que é um arbusto advindo de regiões da Bolívia e Peru. Ela é uma droga "estimulante do sistema nervoso central, agindo sobre ele com efeito parecido ao das anfetaminas. [...] a droga age sobre o sistema nervoso periférico, inibindo a reabsorção, pelos nervos, da norepinefrina (uma substância orgânica similar à adrenalina)". A cocaína em forma de pó leva de $10 \mathrm{a}$ 15 minutos para agir no organismo e seu efeito dura aproximadamente 30 minutos, já que a droga é rapidamente metabolizada pelo corpo.

No que diz respeito à dependência que a cocaína produz no sujeito, Fuchs, Wannmacher e Ferreira (2006, p. 618) afirmam que "caracteriza-se como 'leve' a dependência física induzida pela cocaína. Não havendo, dessa forma, a necessidade de desintoxicação, por não ocorrer dependência física grave”. Já Carlson (2002, p. 584) afirma que a cocaína não produz dependência física, pois "os indivíduos que a ingerem não apresentam tolerância e se pararem de ingeri-la não demonstram sintomas físicos significantes de abstinência”. Isso fez com que, no passado, alguns estudiosos negligenciassem o fato de ela causar dependência.

\subsection{Mecanismo de ação da cocaína}

Segundo Cardoso e Sabbatini (1999), no funcionamento normal de um cérebro, ou seja, sem uma substância química como a cocaína, os neurotransmissores como a dopamina, noradrenalina e serotonina são sintetizados por certas células nervosas que agem em regiões do cérebro promovendo, entre outros efeitos, a motivação e o prazer. Com a entrada da cocaína no cérebro, ocorre um bloqueio nos canais que transportam a dopamina. Quando a cocaína bloqueia os sítios, a dopamina não é recaptada, e fica no cérebro até que a droga saia. "Quando um novo impulso nervoso chega, mais dopamina é liberada na sinapse, mas ela se acumula no cérebro por seus sítios recaptadores estarem bloqueados pela cocaína" (CARDOSO; SABBATINI, 1999). Acredita-se que 
essa presença de dopamina no cérebro por mais tempo é que dá a sensação de prazer associada ao uso dessa droga. "[...] O uso prolongado da cocaína pode fazer com que o cérebro se adapte a ela, de forma que ele começa a depender desta substância para funcionar normalmente diminuindo os níveis de dopamina no neurônio" (CARDOSO; SABBATINI, 1999).

Já Cardoso e Sabbatini (1999), no que diz respeito à síndrome de abstinência, explicam que se o sujeito que usou cocaína por um longo período de tempo parar de usar a substância, não vai ter dopamina suficiente nas sinapses, sendo assim, ele terá o oposto do prazer, ou seja, a síndrome de abstinência, com sintomas tais como depressão, fadiga, humor alterado, entre outros.

\subsection{Os efeitos da cocaína}

De acordo com Fuchs, Wannmacher e Ferreira (2006, p. 618), no que diz respeito às sensações e às emoções que a cocaína acarreta para o usuário, afirmam que eles são divididos em dois patamares. "O primeiro é atingido com doses mais baixas, geralmente empregadas por via nasal, que induzem sensação de bem-estar, diminuição de ansiedade, aumento de capacidade física, autoestima e sexualidade". Os efeitos do segundo patamar ocorrem, segundo os autores, com "o aumento da dose ou a utilização de vias que propiciam maior biodisponibilidade (intravenosa e respiratória)". Neste segundo patamar ocorre "acentuada euforia e uma sensação descrita como um orgasmo continuado". Acrescentam Cardoso e Sabbatini (1999) que a cocaína dá ao indivíduo uma sensação de magnificência, prazer, euforia, excitação sexual, a pessoa torna-se ativa, tagarela, desperta e corajosa.

\subsection{Achados laboratoriais}

Carlson (2002) cita que alguns pesquisadores começaram a estudar a genética para saber se encontram alguma relação com o uso de drogas. Ele aponta que os estudos mostram que a herança genética parece ter uma influência na dependência. Segundo Bierut (1998), em seu estudo que comparou irmãos, "[...] sugere que existam, tanto fatores genéticos gerais, quanto fatores genéticos específicos envolvidos na dependência de substâncias como o álcool, a cocaína, a maconha e a nicotina." (BIERUT apud CARLSON 2002, p. 603).

Estudos foram feitos na tentativa de empregar medicamentos para inibir o uso da cocaína. Pilla et al. (1999) citam a descoberta de uma substância denomina- da BP897 que, quando injetada no rato, funciona da seguinte maneira: "sua ação depende do nível de dopamina presente na sinapse: quando o nível de dopamina é baixo, a droga funciona como agonista, mas quando o nível é alto, ela funciona como antagonista." (PILLA et al. apud CARLSON 2002, p. 589).

Petit e Juice (1989), Di Ciano et al. (1995), Wise et al. (1995) realizaram estudos que mostram que "injeções intravenosas de cocaína e de anfetamina aumentam a concentração de dopamina no núcleo acumbens". Sendo assim, indicam Mc Gregor e Roberts (1993); Caine et al. (1995) que, "se drogas que bloqueiam os receptores de dopamina forem injetadas no núcleo acumbens, a cocaína perde boa parte de seu efeito reforçador" (PETIT; JUICE, 1989), Di Ciano et al. (1995), Wise et al. (1995), Mc Gregor e Roberts (1993), CAINE et al. (1995 apud CARLSON 2002, p. 595).

Caine e Hoob (1994) constataram que, se o núcleo acumbens for lesionado, ou se os terminais que levam os neurotransmissores como a dopamina, por exemplo, forem destruídos por meio de uma injeção de 6-HD no local, isso vai interferir nos efeitos reforçadores da cocaína (CAINE; HOOB apud CARLSON, 2002).

Já Carrera et al. (1995) propõem a criação de uma vacina para aqueles que abusam da cocaína. Por meio de um estudo, eles testaram ratos, para que estes desenvolvessem anticorpos contra a droga. Para isso, eles combinaram a cocaína com uma proteína exógena. O resultado foi que os ratos "imunizados com cocaína eram menos sensíveis aos seus efeitos ativadores e os níveis cerebrais de cocaína nesses animais eram menores, após uma injeção da droga" (CARRERA et al. apud CARLSON, 2002, p. 607).

Lembra Carlson (2002) que essas drogas que estimulam os receptores de dopamina, apesar de poderem interferir positivamente no uso da substância, ou seja, diminuí-lo, têm tanto potencial para desenvolver dependência quanto a própria cocaína. Acrescentam Fuchs, Wannmacher e Ferreira (2006) que, apesar dos estudos, ainda não há evidências de que o uso de medicamentos para inibir o uso da droga promovam de fato o abandono da cocaína.

\subsection{O Behaviorismo Radical}

De acordo com Chiesa (2006, p. 190), o Behaviorismo "é um movimento histórico concentrado nas preocupações científicas e metodológicas e, nesse processo, 
promoveu mudanças em direção a métodos mais consoantes com aqueles das ciências naturais". Nesse sentido, o querer e a vontade, assim como muitos outros termos utilizados por nossa sociedade, são, na verdade, comportamentos que o sujeito apresenta de acordo com sua história de reforço não tendo nada a ver com a explicação mentalista de uma força interna ou mesmo uma energia que move o sujeito a agir de determinada maneira e não de outra. Lembra a autora que "o uso dessas descrições, como se fossem entidades causais, impulsos, forças ou motivadores, é meramente circular", ou seja, não define nem explica nada. Assim sendo, é a consequência passada que controla o meu comportamento presente, pois nosso comportamento é direcionado para o passado e não ao futuro. $\mathrm{O}$ evento futuro não tem como controlar o comportamento, pois ele ainda não aconteceu e pode nem acontecer (CHIESA, 2006).

Afirma Baum (1999, p. 29) que a noção de livre-arbítrio tão aceita pelo senso comum "supõe um terceiro elemento além da hereditariedade e do ambiente, supõe algo dentro do indivíduo". No entanto, na visão behaviorista, o comportamento é produto, apenas, da relação organismo/ambiente e, portanto, segundo Todorov (1981), o homem é visto como "parte da natureza nem pairando acima do reino animal, como o viram pensadores pré-darwinianos, nem mero robô, apenas vítima das pressões do ambiente [...]”. Nesse sentido, de acordo com Baum (1999, p. 210), "o homem é em grande parte responsável pelo ambiente em que vive".

Devemos salientar que a visão da fisiologia e a da análise do comportamento não são incompatíveis, entretanto, no que diz respeito àquilo que é sentido ou observado dentro do sujeito, ou seja, processos fisiológicos ou neurais. Skinner (1974, p. 215) diz que eles não são capazes de "preencher a lacuna temporal de uma analise histórica”. Corroborando essa ideia, Tourinho, Teixeira e Maciel (2000) afirmam que nem as explicações mentalistas que se utilizam da introspecção, nem as explicações de processos fisiológicos sobre o que acontece quando o sujeito se comporta têm dado respostas satisfatórias sobre o que acontece interiormente quando um determinado sujeito está se comportando. Essas explicações têm tido apenas o efeito de tirar a atenção do ambiente em que o sujeito se encontra. No entanto, lembram os autores através de uma fala de Skinner (1988/ 1989, p. 82) que “[...] para cada terapeuta comportamental que, após descobrir um fato sobre o comportamento, procura uma explicação fisiológica, há um terapeuta a menos para estudar mais o próprio comportamento." (SKINNER apud TOURINHO; TEIXEIRA; MACIEL, 2000) E acrescentam Silva, Guerra e Alves (2005) que a valorização das observações de processos neurais pode dar ênfase no lado orgânico de um determinado distúrbio, patologizando o comportamento e fomentando assim a criação de uma prática com foco no uso de medicamentos como tratamento.

\subsection{Os três níveis de seleção de Skinner}

Skinner cita três níveis de seleção do comportamento humano: o primeiro nível é a seleção filogenética a qual não vemos acontecer, pois ela ocorre ao longo de muitos anos. Um exemplo citado por Baum (1999) é a extinção de espécies que não sobreviveram por questões de não adaptação ao ambiente. Isso significa que, na seleção natural ou filogenética, os genótipos daqueles que sobrevivem ao ambiente são passados lentamente de geração para geração, num ambiente que permanece por muito tempo estável. Cita Skinner (1984, p. 326) que a ontogênese cumpre o papel de suprir essa falha deixada pela filogênese da seguinte maneira: "o comportamento ontogenético pode permitir a uma espécie manter-se num determinado ambiente por um longo tempo e, assim, tornar possível a atuação das contingências filogenéticas.”.

Muitas espécies, dentre elas a humana, são aptas a reconhecerem as consequências de seu próprio comportamento. Nesse sentido, diz Baum (1999) que podemos dizer que temos preparação fisiológica para o condicionamento operante. E é a própria filogênese que seleciona o comportamento de aprender, ou seja, o comportamento operante, pois o mundo está em constante mutação e, portanto, a seleção filogenética não seria possível em um curto período de tempo. Assim, o sujeito que aprendeu com as consequências de seu comportamento e que, consequentemente, se adaptou melhor ao ambiente, sobreviveu e pôde perpetuar a espécie. O segundo nível de seleção pelas consequências descrito por Skinner é justamente a seleção ontogenética. Essa seleção do comportamento ocorre na vida do indivíduo no presente e o comportamento é alterado pelas consequências, mas a alteração é imediata e não a longo prazo. A seleção do comportamento atual do indivíduo ocorre por generalização e discriminação de estímulos, de acordo com a história de reforçamento do indivíduo. Os comportamentos selecionados são, geralmente, aquelas respostas que permitam 
uma boa adaptação ao ambiente. (BAUM, 1999).

O condicionamento operante, de acordo com Micheletto e Sério (1993), só acontece após o aparecimento da primeira resposta. Porém, uma primeira resposta nem sempre acontece e essa lacuna é preenchida pela cultura. O terceiro nível de seleção do comportamento humano é a seleção cultural, ou, como cita Chiesa (2006), a seleção das "práticas culturais", que consiste em aprender com o outro. A partir do momento em que o comportamento operante de uma pessoa emite controle sobre meu comportamento, eu posso ser melhor adaptado. Na seleção cultural, por meio do comportamento do outro, eu adquiro repertório comportamental. Nesse sentido, culturas são selecionadas sobrevivendo àquelas que estiverem sendo eficientes, portanto a sobrevivência é o critério de eficiência de uma cultura, pois, quando práticas de controle não estão mais funcionando, elas são substituídas. Esse critério de sobrevivência como eficiência ocorre nos três níveis de seleção.

Acrescenta a autora que cada nível de seleção é uma preparação para o próximo. Sendo assim, a filogênese prepara o organismo para a ontogênese que prepara o sujeito para a seleção cultural. Corroborando essa ideia, de acordo com Skinner (1974, p. 168), "uma pessoa [...] possui uma dotação genética de características anatômicas e fisiológicas que são o produto das contingências de sobrevivência as quais a espécie esteve exposta durante o processo de evolução". Isso significa que o aparato biológico é feito, ou moldado, na relação do indivíduo com a natureza (ambiente). Ou seja, diz Chiesa (2006, p. 100) que "o comportamento atual (a pessoa) nesta visão resulta de uma dotação genética única, de uma história de reforço única (experiência de vida) e das relações com o ambiente atual" e os padrões comportamentais de cada sujeito são selecionados, mantidos e fortalecidos frente a uma gama de possibilidades por eventos antecedentes, ou seja (história de reforço) e eventos consequentes, ou seja (consequências do comportamento do indivíduo). Lembra Baum (1999, p. 80) que "os reforçadores e punidores, direta ou indiretamente, derivam [...] de uma história de evolução por seleção natural". Com isso, os próprios reforçadores do comportamento passaram, também, por uma seleção para serem considerados como tal.

\subsection{O ambiente para a análise do comportamento}

O ambiente para a análise do comportamento tem fundamental importância para se entender o com- portamento. Skinner (1953/1965) define ambiente como "eventos do universo capazes de afetar um organismo" (SKINNER apud TOURINHO; TEIXEIRA; MACIEL, 2000). De acordo com Todorov (1981), o ambiente é considerado pela análise do comportamento em quatro aspectos, nesse sentido, o ambiente é físico, social, biológico e histórico. Mas lembra ele que essa divisão é apenas didática, pois um aspecto acaba sendo indissociável dos outros, ou seja, aspectos biológicos estão presentes no histórico, aspectos físicos estão presentes no social e assim por diante.

Para um melhor entendimento dos quatro aspectos, como exemplo de ambiente biológico, podemos citar processos fisiológicos ou mesmo uma dor de barriga. Já o ambiente físico nada mais é do que o ambiente material no qual o sujeito se encontra inserido. O social são as pessoas a minha volta, minha comunidade verbal, minha cultura. E, finalmente, o ambiente é visto pela análise do comportamento como histórico na medida em que tem a ver com o repertório comportamental adquirido pelo sujeito ao longo de sua vida, ou seja, o que aconteceu, em um momento anterior nesse mesmo ambiente. Assim, segundo Todorov (1981), as interações entre o organismo e seu ambiente, no passado, cumprem função importante na hora de se explicar as interações presentes. Por isso, a resposta que o indivíduo emite altera o ambiente e essa alteração é uma consequência do seu comportamento. Nesse sentido, o sujeito age e modifica o mundo (ambiente) que é modificado e por isso gera as consequências desse comportamento (comportamento operante) (TODOROV, 1981).

\subsection{Os mecanismos de ação da droga na visão analí- tico comportamental}

A forma como os três primeiros subtópicos do desenvolvimento explica o uso da droga é puramente mecanicista e não será reproduzida nesta parte do artigo, visto que se trata nesta seção da visão da análise do comportamento em relação ao uso da cocaína. Assim, não vamos pensar nos efeitos da droga como uma relação de causa e efeito, mas sim como uma relação regular (CHIESA, 2006). O que foi observado até agora é que determinados comportamentos fisiológicos do organismo ocorrem sempre que se ingere tal droga, mas isso não significa que o comportamento ocorreu por causa da droga. Nessa abordagem o comportamento é visto como algo determinado, ordenado e regular para poder ser estudado pela 
análise do comportamento, pois ele isolado do ambiente não diz nada, e por isso temos que considerar o contexto em que o comportamento ocorreu. Trata-se de um fluxo, pois um comportamento altera o outro que altera o outro. Observa-se, também, que há uma regularidade entre eles, no entanto, mais uma vez vale salientar que não se trata de causa (ambiente) e efeito (comportamento), mas sim uma regularidade entre eles, pois caminham juntos. Nesse sentido, uma mudança em um comportamento é igual à mudança em outro. Isso diz respeito a uma regularidade, pois o comportamento é produto de uma relação funcional, em que a consequência do próprio comportamento é o que o determina (CHIESA, 2006).

No entanto, as explicações de fora do Behaviorismo têm se utilizado de estruturas mediadoras ou constructos hipotéticos para explicar o comportamento de adicção a drogas e, dessa maneira, acaba não explicando o comportamento como podemos perceber nessa citação de Barron, et al. (1970):

é preciso enfatizar sempre que a reação a essas drogas depende não só das propriedades químicas e da atividade biológica das drogas, mas também do contexto no qual elas são tomadas, no sentido de tal ato e da personalidade e estado de espírito do indivíduo que as toma. Se o ato de tomar a droga é definido pelo indivíduo como imoral ou criminoso, podemos esperar, com resultado, culpa e agressão, com posterior delinquência social; se o objetivo é auxiliar ou ser auxiliado, a experiência pode ser terapêutica e reforçadora; se o sujeito teme a psicose, a droga pode induzir a psicose (BARRON, et al. 1970, p. 398 , grifo nosso).

No que diz respeito à utilização da fisiologia ou neurologia pela psicologia para explicar o uso de drogas pelo sujeito, podemos dizer que qualquer alteração fisiológica no organismo só faz sentido para a análise do comportamento no momento em que modifica o comportamento do sujeito. Além disso, apenas o aspecto fisiológico não dá conta de explicar o comportamento de uso de uma droga pelo sujeito, mesmo porque o efeito da droga é suscetível a uma série de eventos e, entre os principais, estão o ambiente e a história de reforçamento do indivíduo. Nesse sentido, os aspectos fisiológicos também são considerados, mas como ambiente, na medida em que afetam o comportamento.

Podemos pensar por dois caminhos para falar sobre o porquê de a droga, mais especificamente a cocaína, ser reforçadora. Primeiro, podemos olhar pelo aspecto fazer com que o organismo libere dopamina no núcleo acumbens da mesma maneira que outros reforçadores chamados de naturais, como é o caso do alimento, da água e do contato sexual. Lembrando que esses reforçadores só assumem essa função em virtude da questão de seleção filogenética para fazer com que o indivíduo se alimente e procrie, garantindo, assim, a perpetuação da espécie. Mas também podemos fazer o caminho inverso ao analisar o porquê de a cocaína ser reforçadora. Podemos pensar que ela se tornou reforçadora por uma questão de generalização de estímulos. Ou seja, o fato de ela historicamente já fazer o organismo liberar dopamina fez com que adquirisse, com a evolução da espécie, valor reforçador por generalização por função, pois ela tem a mesma função que os reforçadores naturais do comportamento, ou seja, fazer com que o organismo libere dopamina que é uma substância relacionada ao prazer.

Barron et al. (1970) levantam duas questões: os sujeitos usam a droga para evitar os efeitos negativos do não uso (sintomas de abstinência) ou a usam pelos efeitos positivos que ela proporciona no organismo? Para a análise do comportamento, essa é uma questão pouco provável de ser respondida, visto que a resposta depende, dentre outros fatores, da história de reforçamento de cada sujeito. Cada indivíduo vai apresentar uma relação com a droga por motivos distintos. Porém, alguns princípios básicos da análise do comportamento dão conta de explicar processos no mecanismo complexo da adicção. Quanto mais rápido uma droga produzir seus efeitos positivos no organismo do indivíduo, mais rapidamente se estabelecerá a dependência. Como é o caso do crack que, de acordo com Cardoso e Sabbatini (1999), demora, aproximadamente, 8 segundos para fazer efeito e por isso causa dependência em poucos dias de uso enquanto a cocaína demora de 10 a 15 minutos para fazer efeito, se caracterizando assim como um reforço tardio. Também acontece que o efeito do crack dura de 1 a 2 minutos, enquanto a cocaína dura aproximadamente 30 minutos.

Para a análise do comportamento, esse fato pode ser demonstrado em experimentos simples com ratos na caixa de Skinner, e é explicado da seguinte maneira: quanto mais rápido o sujeito for reforçado, maior será a eficácia do reforço. Em relação ao tempo de duração do efeito da droga no organismo, podemos dizer que aquela que tem tempo de duração menor faz com que o sujeito intensifique o uso, usando a droga "uma atrás da outra" para poder ser reforçado. Com relação à diminuição 
dos efeitos reforçadores da droga com o tempo, Skinner (1984, p. 220) diz que "a medida que se desenvolve o vício, o viciado deve ingerir cada vez mais da droga [...] para conseguir um dado efeito. Na medida em que a novidade é importante, todos os reforços têm sua eficácia diminuída com o tempo [...]".

No que diz respeito à utilização de medicamentos para inibir o uso por usuários de cocaína, Skinner (1984) cita o exemplo de drogas para inibir o uso do cigarro que pode ser usado aqui. Diz ele que é possível usar medicamentos para inibir o uso, mas que aconteceria apenas uma redução no efeito de alguns reforçadores no comportamento de fumar, não eliminando, assim, o comportamento problemático por completo. $\mathrm{O}$ autor defende, então, que seria mais fácil e eficiente fazer o uso do controle das contingências de reforço para manipular esse comportamento de uso de droga, pois uma alteração no controle de estímulos acarreta uma mudança no valor da estimulação e, consequentemente no padrão comportamental do sujeito (SKINNER, 1984).

A questão genética sobre a probabilidade de desenvolver dependência é difícil de ser respondida com total certeza, pois essa probabilidade pode tanto ser genética, como pode ser um comportamento imitativo. Por exemplo, para um sujeito que viu seu pai emitindo a resposta de usar a droga como fuga frente a uma estimulação aversiva, como problemas no trabalho, problemas com a esposa, entre outros, existe a probabilidade de que o filho, frente a problemas similares durante a vida, apresente o mesmo padrão de resposta. Sendo assim, um comportamento imitativo do que ele aprendeu no decorrer de sua história de reforçamento.

De acordo com Carlini et al., (2002), as faixas etárias que apresentam o maior uso de cocaína são, em primeiro lugar, a de 25 a 34 anos com 4,4\% e a de 18 a 24 anos com 3,2\% em segundo lugar com uma prevalência em ambos os casos de sujeitos do sexo masculino. Essa faixa etária é acompanhada pela aquisição de responsabilidades e decisões importantes na vida de um sujeito. Diz Skinner (1984, p. 225) que "muitas drogas, das quais o álcool talvez seja o melhor exemplo, têm consequências reforçadoras; e a ingestão de drogas é também comum quando os negócios sérios da vida podem ser postos de lado". Nesse sentido, é provável que o comportamento de uso da cocaína esteja concentrado nessa faixa etária como um comportamento de fuga ou esquiva de situações tradicionalmente aversivas referentes à idade.
Percebe-se que muitos usuários de substâncias psicoativas tentam o suicídio como uma forma de fugir do sofrimento pelo qual estão passando. Isso pode ser explicado pela análise do comportamento como um contra controle do indivíduo frente a droga que está controlando seu comportamento. A tentativa de suicídio é um comportamento de esquiva que sinaliza a probabilidade de eliminação da estimulação aversiva. Essa estimulação aversiva não diz respeito apenas aos efeitos negativos que o químico traz para o sujeito, a chamada síndrome de abstinência. Uma inferência possível é de que isso decorra de uma provável desaprovação da família e ou da sociedade na qual o sujeito se encontra inserido ou mesmo um comportamento de cobrança partindo do próprio sujeito para com ele mesmo. Nessa perspectiva, podemos citar o exemplo do comportamento de fuga e esquiva do rato dentro da caixa de Skinner.

Devemos acrescentar que a influência que o grupo exerce sobre o comportamento de seus membros é uma variável ambiental que deve ser considerada, pois é sabido pela análise do comportamento que, quando o sujeito se comporta como o grupo, ele tem maior probabilidade de ser reforçado. Sendo assim, podemos citar o exemplo de um grupo de adolescentes que fazem uso de uma determinada substância. Todos os sujeitos pertencentes ao grupo, provavelmente, usarão essa substância para não entrar em contato com estimulações aversivas, vindas do restante do grupo.

Pode-se dizer que, de uma maneira geral, a consequência imediata é mais reforçadora do que a consequência em longo prazo. Como exemplo, podemos citar o uso da cocaína e as possíveis consequências que ele pode acarretar para o sujeito. A possibilidade de sofrer uma overdose é uma consequência a "longo prazo" e pouco provável, pois pode ocorrer a qualquer momento, até mesmo no primeiro uso, mas pode nem ocorrer. Assim, essa consequência é pouco eficiente no controle do comportamento do sujeito no presente, visto que as consequências que o uso da droga proporciona para o sujeito no momento presente são mais reforçadoras do que as consequências futuras. Isso significa que as consequências em longo prazo são menos eficientes no controle do comportamento. Mas não podemos nos esquecer que uma estimulação ser reforçadora ou não vai depender da história de reforçamento de cada indivíduo.

Com relação aos ganhos que o sujeito experimenta quando faz uso da substância psicoativa, devemos lem- 
brar que cada experiência é única, devido à história de reforço de cada indivíduo em particular. Nesse sentido, as possibilidades de ganhos que o sujeito experimenta são infinitas, devido à complexidade do comportamento. Mas, como exemplo, podemos citar um sujeito que relata usar a cocaína como forma de manter-se bem-humorado, mais esperto ou desinibido. Ou mesmo para se esquivar de um casamento que ele considera desgastado e até para amenizar os estímulos aversivos da cobrança do chefe no trabalho. Alguns sujeitos, quando sob o efeito da droga, podem apresentar comportamentos que não apresentariam se não estivesse sob o efeito da mesma. Sendo assim, a droga se torna muitas vezes reforçadora para aqueles que apresentam repertório comportamental social pobre e que, portanto, apresentam comportamentos tais como vergonha, inibição, entre outros.

A cocaína, para um determinado indivíduo, pode cumprir o papel de estabelecer confiança e diminuir a timidez, isso vai depender da relação que aquele sujeito tem com aquela droga e, é claro, da sua história de reforçamento. Mas o que importa para nós é observar que as drogas alteram o padrão comportamental do sujeito que as usa. Isso pode ser um dos grandes mantenedores do comportamento de adição, pois, quando o sujeito não tem repertório comportamental para se relacionar com as pessoas e o consegue fazendo uso da droga, seu comportamento está sendo reforçado.

\section{Considerações finais}

A análise do comportamento vê o uso da cocaína diferentemente da visão apresentada por ciências mecanicistas de explicações internalistas. Essa abordagem considera o comportamento como o produto de uma relação funcional, em que a consequência do próprio comportamento é o que o determina. Foram as seleções por consequência, seja a nível filogenético, ontogenético ou cultural, em conjunto com variáveis ambientais que trouxeram o homem a sua condição atual. E, nesse sentido, o ambiente (físico, biológico, social e histórico) desempenha papel fundamental.

Devemos salientar que o comportamento de abuso de substâncias, considerado pela sociedade como um comportamento problemático do sujeito, é, na verdade, um problema da sociedade na qual o indivíduo se encontra inserido. Sendo assim, é um comportamento proble- víduo e a sociedade (ambiente) na qual ele vive.

No que diz respeito à lógica da fisiologia ou da neurociência de localizar no cérebro a área ou região que "comanda" um determinado comportamento, não é útil para a análise do comportamento na medida em que não dá conta de explicar o próprio comportamento. Porém, é necessário considerar a importância e eficiência dessas disciplinas no que diz respeito à sua área de atuação.

Uma solução possível para Skinner (1984, p. 218) no que diz respeito ao controle do comportamento de uso da droga seria não deixar o sujeito ser "fisgado" por ela, ou seja, não deixar que ele entre em contato com a substância. Cita ele, "podemos minimizar algumas consequências indesejáveis evitando a descoberta de efeitos reforçadores". Outra proposta seria estabelecer um padrão comportamental no sujeito de modo que ele não precise fazer uso de substâncias psicoativas, ou seja, criar condições para que o sujeito não veja a droga como um reforçador. Nesse sentido, também poderia ser eficaz, diminuir a aversividade da vida cotidiana do indivíduo. Por exemplo, no caso de um sujeito com repertório comportamental pobre para relacionar-se socialmente com outros sujeitos, o que Skinner propõe é que se estabeleça esse repertório no seu comportamento para que ele não recorra a outros meios, como a droga para relacionar-se com outras pessoas.

Um primeiro passo para uma eficácia do tratamento do usuário de cocaína é fazer com que o uso da droga se torne minimamente aversivo para o sujeito para que se consiga mudanças no seu comportamento, pois, se o comportamento de uso da droga continuar sendo reforçador para ele, seu comportamento vai continuar sendo mantido. Nesse sentido, devemos criar condição para que o valor reforçador da droga seja diminuído, tornando-a aversiva para o usuário, ou menos reforçadoras que alternativas mais saudáveis ao sujeito e a sociedade em que se encontra inserido.

Sendo assim, o analista do comportamento que se propõe ao tratamento de usuários de cocaína, além de entender os mecanismos de ação da droga no organismo do sujeito, deve entender quais são as relações mantenedoras do comportamento de uso da droga para aquele sujeito especificamente para assim poder alterá-las. Assim, uma análise funcional realizada de forma adequada, por um profissional que domine os princípios da análise do comportamento, identifica as variáveis ambientais que têm mantido o comportamento do sujeito. 
E, para finalizar, gostaria de citar uma frase de Skinner (1984, p. 221) que resume a proposta behaviorista radical no tratamento do uso abusivo de drogas, diz ele que "não requereria nenhuma mudança no comportamento humano por meios químicos, cirúrgicos ou mesmo genéticos, uma vez que uma sensibilidade natural ao reforçamento passa a ser agora mais útil do que geradora de problemas".

\section{Referências}

BARRON, F.; MURRAY, E. J.; BUNNET, S. Psicobiologia: as bases biológicas do comportamento. Tradução de Lidia Aratangy. São Paulo: Polígono, 1970.

BAUM, W. M. Compreender o behaviorismo: ciência, comportamento e cultura. Tradução Maria Teresa Araujo Silva. Porto Alegre: Artes Médicas Sul, 1999.

CARDOSO, S. H.; SABBATIN, R. M. E. Os efeitos da cocaína no cérebro. Revista Cérebro e Mente, Campinas, v. 3, n. 8, jan./mar. 1999. Disponível em: <http://www.cerebromente.org.br/n08/doencas/drugs/anim1.htm $>$. Acesso em: 18 jan. 2015.

CARLINI, E. A. et al. I Levantamento domiciliar sobre o uso de drogas psocotrópicas no Brasil: estudo envolvendo as 107 maiores cidades do país. Centro Brasileiro de Informações Sobre Drogas Psicotrópicas (CEBRID). São Paulo: Universidade Federal de São Paulo, 2002.

CARLSON, N. R. Fisiologia do comportamento. 7. ed. Barueri: Manole, 2002.

CHIESA, M. Behaviorismo radical: a filosofia e a ciência. Tradução Carlos Eduardo Cameschi. Brasília: Ibac e Celeiro, 2006
FUCHS F. D.; WANNMACHER, L. E; FERREIRA, M. B. C. Farmacologia clínica: fundamentos da terapêutica racional. 3. ed. Rio de Janeiro: Guanabara Koogan, 2006.

SILVA, M. T. A.; GUERRA, L. G. G. C.; ALVES C. R. R. Modelos comportamentais em neurociências. Revista Brasileira de Análise do Comportamento. v. 1, n. 2, p. 167185, 2005. Disponível em: <http://www.rebac.unb.br/ vol1_2/rebac_silva_etal_2005.pdf $>$. Acesso em: $17 \mathrm{mar}$. 2010.

SKINNER, B. F. Seleção por consequências. Disponível em: $\quad<\mathrm{http}: / / \mathrm{www}$.inpaonline.com.br/artigos/profissionais/selecao_consequencias.htm $>$. Acesso em: 06 jan. 2015.

SKINNER, B. F. Sobre o behaviorismo. São Paulo: Cultrix, 1974.

SKINNER, Burrhus Frederic; PAVLOV, Ivan Petrovich. Textos escolhidos e contingências de reforço. Tradução de Rachel Moreno, Hugolino de Andrade Uflaker e Elena Olga Maria Andreoli. 2. ed. São Paulo: Abril Cultural, 1984.

TODOROV, J. C. A psicologia como o estudo das interações, 1981. Disponível em: <www.cemp.com.br/artigos. asp?id=29>. Acesso em: 03 abr. 2010.

TOURINHO, E. Z.; TEIXEIRA E. R.; MACIEL, J. M. Fronteiras entre análise do comportamento e fisiologia: Skinner e a temática dos eventos privados. Revista Psicologia: reflexão e crítica, v. 13, n. 3, p.425-434, 2000. Disponível em: <http://www.scielo.br/pdf/prc/v13n3/ v13n3a11.pdf>. Acesso em: 12 jan. 2015. 